\title{
Supraclavicular Fossa
}

National Cancer Institute

\section{Source}

National Cancer Institute. Supraclavicular Fossa. NCI Thesaurus. Code C142323.

A depression found at the base of the neck that is bounded thusly: superiorly by the posterior belly of the omohyoid muscle; inferiorly by the clavicle; and medially by the sternocleidomastoid muscle. 